\title{
How moral disagreement may ground principled moral compromise
}

Kappel, Klemens

Published in:

Politics, Philosophy \& Economics

DOI:

$10.1177 / 1470594 X 17729132$

Publication date:

2018

Document version

Peer reviewed version

Citation for published version (APA):

Kappel, K. (2018). How moral disagreement may ground principled moral compromise. Politics, Philosophy \& Economics, 17(1), 75-96. https://doi.org/10.1177/1470594X17729132 


\section{How moral disagreement may ground principled moral}

\section{compromise $^{\#}$}

By Klemens Kappel, University of Copenhagen, July 2017

Forthcoming in Politics, Philosophy and Economics

\section{Introduction}

There is pervasive disagreement about morally laden policy issues such as genetically modified crops, abortion, gun control, taxation, assisted death, same sex marriage, the death penalty, the minimum wage, public health and medical care. In these and similar cases, moral disagreements frequently underlie

\# Earlier and somewhat different versions of some of the ideas discussed were presented at Early versions of some of the ideas discussed in this paper were presented at workshops and conferences held at the University of Copenhagen in August 2014 and May 2015. Thanks to Simon C. May, Daniel Weinstock, Fabian Wendt, Xavier Landes, Karin Joench-Clausen, Christian Rostbøll and others present at these occasions for stimulating discussion. Thanks in particular to Martin Marchman for many discussions of these issues. 
divergent views as to what policies should be adopted. These moral disagreements are often recalcitrant - parties to the disagreement fail to be moved by their counterpart's arguments and views, or at least fail to reach a consensus. It is a commonly held view that when we face policy disagreements rooted in persistent moral disagreement, we should at least sometimes come to a compromise. ${ }^{1}$

In an influential paper, Simon C. May has forcefully argued that, properly understood, there can never be what is termed principled reasons for moral compromise (May 2005). ${ }^{2}$ Unquestionably, there may be pragmatic reasons for compromising that involve, for instance, concern for political expediency or for stability. But properly understood, principled reasons to compromise are illusory - they don't exist. 1992; Bellamy \& Hollis 1999). see (May 2011). 
My aim in this paper is to show how principled moral compromise in the context of moral disagreements over policy options is possible. While May argues that disagreement can never ground a principled reason to depart from the all things considered best position in favor of a compromise, I argue that when we disagree, principled reasons favoring compromises or compromising can assume a more significant part of what makes a position all things considered best.

The paper will proceed as follows. Section 2 seeks to characterize the notion of a moral compromise. In Section 3 I distinguish between different types of reasons for compromise. In section 4 I review May's argument against the possibility of there being principled reasons for moral compromise. Sections 5 through 7 develop an account of how disagreement about moral questions paves the way for moral compromise. In Section 8 I consider some objections to the account developed, and in Section 9 I make a few concluding remarks.

\section{Moral Compromises}

I begin by clarifying what is to be understood by a moral compromise. To do so, it is convenient to work with an example, albeit a very schematic one: 
Adele and Betty disagree about some moral issue, and as a result, they disagree about which policy to adopt in the relevant domain. Having discussed their respective convictions and exchanged arguments extensively, they are entirely familiar with one another's position. Both Adele and Betty have formed stable views that are not about to change. All possibilities of adding new policy options to the table, or of devising policy options that meet more of each party's desiderata, have been explored to no avail. ${ }^{3}$ On the one hand, Adele espouses the moral view $\mathrm{P}$, and based on this, prefers policy $\mathrm{X}$. Betty, on the other, is committed to the moral view $Q$, which results in her belief that policy $Z$ is best. $\mathrm{Y}$ is a position that is located between $\mathrm{X}$ and $\mathrm{Z}$ on the spectrum of policy possibilities. substitutive compromises (Weinstock 2013). Here and throughout, I consider reasons for compromise relative to a fixed set of options. So if integrative or substitutive compromises are available, they have already been included within the list of policy options. 
This is the paradigmatic type of case that I will have in mind throughout the discussion. The case illustrates a schema that provides a plausible constraint on what counts as compromise: for some policy option $Y$ to count as a compromise, it must be located between salient extremes $\mathrm{X}$ and $\mathrm{Z}$, each respectively preferred by the compromising parties. $^{4}$

A couple of things should be noted. First, $X, Y$ and $Z$ are policy options and not moral views. So, I assume that what compromises concerns policy options, not moral views. I also assume that in the cases we are concerned with, support for policy options are motivated at least in part by moral concerns. This is why it is appropriate to talk about moral compromise, even though, as just noted, we compromise about policy options and not basic moral commitments. It is not clear what sense it makes, if any, to compromise on one's basic moral commitments, but we can set this question aside.

Second, in most of the discussion, I assume that $X$ and $Z$ are policy options placed at the far ends of a spectrum, and that $Y$ is a position located somewhere between $X$ and $Z$. In many realistic cases there will be indefinitely 
many positions that qualify as compromise positions in this schematic sense. Consider, for example, a disagreement over progressive taxation. Some argue that there should be a steep progressive taxation, say $80 \%$ for very high incomes, and the basis for holding such a position may be morally motivated (after all, those who earn a lot do so in great part because of luck). Others are in favor of a regressive taxation, such that high earners effectively pay a lesser fraction of their income in tax (say, because of moral views about self-ownership and entitlement to whatever your skills and circumstances can earn you). Obviously, there are indefinitely many positions in between these two extremes, including positions that are arbitrarily close to either extreme. ${ }^{5}$

A full account of moral compromises would need the notion of a fair compromise, where this is not simply any position between extreme positions, even if the extreme positions are somehow both reasonable. Evidently, when we seek compromises, what we typically want are compromises that are fair. Establishing a metric for the fairness of compromises is a difficult challenge. For an interesting discussion of the notion of a fair compromise, see (Jones \& O'Flynn 2012) 


\section{Reasons and compromises}

Consider now what it is to have a reason to compromise. First, recall the familiar distinction between instrumental (or pragmatic) reasons and noninstrumental (or principled) reasons. We often have instrumental reason to accept a compromise, say in the interest of ongoing collaboration, or because we wish to preserve stability. Indeed, in many cases, such instrumental concerns provide strong or even overriding reasons for accepting a compromise. However, like May and others, I set aside instrumental reasons for compromise, and focus strictly on non-instrumental reasons, or what are often referred to as principled or moral reasons for compromise. Henceforth, when I speak about reasons for compromises and compromises, I mean principled or moral reasons for compromises and principled or moral compromises. To elaborate further, consider this expansion of the case provided above:

Adele has in fact (and, what she justifiably takes to be) the all things considered best view on the moral issue in question, and a fully legitimate procedure of reasoning has given Adele her favored policy X. Betty fully acknowledges the legitimacy of that procedure, and accepts to abide by $\mathrm{X}$ even though she still 
thinks that $Z$ would be a superior policy. So, policy $X$ will prevail unless Adele decides to concede $Y$ so as to reach a compromise with Betty.

As the case is set up, Adele is by no means under pressure to accept a compromise, and there are no instrumental reasons in favor of her doing so. Assume that this means that if Adele has any reason to consent to a compromise at all, that reason will be a moral reason or a principled reason, and we thereby get some grasp of these notions (cf. May 2005: 319ff). ${ }^{6}$

We now need to distinguish between several types of principled reasons for accepting a compromise. Consider first what pro tanto reasons to compromise. By this I mean a factor or consideration that count in favor of compromise. Of course, pro tanto reasons for compromise can exist along with with pro tanto reasons against. Sometimes the balance of pro tanto reasons for reasons from moral reasons in all cases. However, it does not affect my argument if it turns out that the class of moral reasons for compromise include part of what might in the first instance consider pragmatic reasons. 
and against may favor a particular option, and we can then say that this option is all things considered best. We might say that when an option is favored by the balance of the pro tanto reasons, then there is an all things considered reason for this option, though this all things considered reason is, of course, not a separate reason but just a composite of the underlying pro tanto reasons. If there is an all things considered reason for accepting some policy option, this just means that this option emerges as best once all relevant factors are taken into account. That is, the balance of reasons favors that option over all other options. Note that even if some option is all things considered best, there may still be some features counting in favor of other options. When this is so, we can say that while the balance of pro tanto reasons favor one particular option - the all things considered best option - there are one or more pro tanto reasons favoring other options.

Suppose that Adele has correctly identified X as the policy that is all things considered best. Could there then be all things considered reasons that favor another option Y? Could Adele coherently believe that there are all things considered reasons for adopting the compromise position Y? Clearly, these 
questions must be answered in the negative. If $X$ is all things considered best, some different option $Y$ cannot be all things considered best as well. ${ }^{7}$ When Adele believes that $\mathrm{X}$ is all things considered best, she cannot coherently think there is an all things considered reason to favor some compromise policy position $\mathrm{Y}$.

This is not so in the case of pro tanto reasons for compromise. Even if $\mathrm{X}$ is the all things considered best policy, there may still be pro tanto reasons counting in favor of some compromise option Y. It is just that the pro tanto reasons favoring $\mathrm{Y}$ are outweighed by other pro tanto reasons favoring $\mathrm{X}$ (otherwise $\mathrm{X}$ would not be all things considered best). So, when Adele correctly identifies $X$ as the all things considered best option, she could surely still good or better than any alternative, then two options could both be all things considered best. We can set this possibility aside. When I refer to an option as all things considered best, I mean that it is strictly better than any other alternative in the relevant set. 
recognize pro tanto reasons that support $Y$, though she would have to commit to holding that the balance of reasons favor $\mathrm{X}$.

We now need to distinguish between various types of pro tanto reasons that may be involved in compromises. Suppose again that $X$ is all things considered best, and that $Y$ is a compromise policy. Now, there might be features of $Y$ that make $Y$ morally attractive independently of $Y$ being a compromise position. Assume, for instance, that $Y$ involves a more equitable distribution of goods than $X$ does, and assume that this is a good-making feature of $X$. In this case, there is a pro tanto reason in favor of policy option $Y$ that does not depend on $Y$ being a compromise position. This good-making feature of $Y$ is not contingent on $Y$ being located between the salient policy extremes $\mathrm{X}$ and $\mathrm{Z}$ at issue in the dispute in question. So, there may be pro tanto reasons for a policy option $Y$ that essentially depend on intrinsic features of $Y$, and not on $\mathrm{Y}$ constituting a compromise relative to other positions.

Other pro tanto reasons for compromise may depend on a position $Y$ being situated as a compromise relative to $X$ and $Z$. Suppose that $X$ is a policy that favors one half of the population, and Z a policy that favors the other half, while $\mathrm{Y}$ is a compromise policy in that it distributes goods evenly between both halves of the population. $Y$ would then have the feature that it splits evenly 
between two salient extreme positions. This feature of $Y$ could support a pro tanto reason in favor of $Y$, where this pro tanto reason would essentially depend on $Y$ being a compromise position between two salient extremes. Henceforth, I refer to this type of reason as a pro tanto reason for a compromise. So, a pro tanto reason for a compromise is a reason in favor of a particular policy option $Y$, where this reason essentially depends on $Y$ being located in between certain contextually salient extremes.

A third type of pro tanto reason does not depend on any particular property of compromise positions, but rather on the process of compromising, i.e. on features of negotiating or altering one's ranking of various policy options in response to disagreement. I will refer to these as pro tanto reasons for compromising, and they should be distinguished from pro tanto reasons for a particular compromise. Pro tanto reasons for compromising are moral reasons that reside in concerns such as that for inclusion, respect, reciprocity, or civic friendship. Concern for procedural fairness or legitimacy may also ground 
reasons for compromising. ${ }^{8}$ If cogent, these are moral reasons for allowing a process of compromising to be part of a decision-making procedure that selects a policy option.

Reasons for compromising are independent of any particular features of the compromise positions salient in a context of disagreement; they are reasons for finding an intermediary position between initial positions held by participants in a decision-making context, and are not reasons for finding any particular feature of salient compromise options attractive. Note also that even if agents have compelling reasons for compromising, these reasons may be entirely unsuited to identifying any one particular compromise position as the most appropriate. And there might be many cases in which there are no sufficiently weighty pro tanto reasons for compromising that single out any particular compromise positions in the spectrum. This adds to the difficulty of determining what constitutes a fair compromise, but fortunately we need not worry about this here. moral reasons for compromising. 
In summary, we need to differentiate between instrumental (or pragmatic) reasons for compromise and principled (or moral) reasons for compromise. Moreover, we should distinguish between reasons for compromises, and reasons for compromising. Finally, we also need to distinguish between a pro tanto reason for a compromise (or for compromising) and a compromise being the all things considered best option.

With these distinctions in mind, return now to the overall question at hand: when we disagree with one another about what to do, do we ever have principled reasons for compromise? As should be clear by now, this question is too blunt. First, as we have seen, if some option $\mathrm{X}$ is best because the balance of pro tanto reasons favors that option, then there cannot be an all things considered reason to favor some compromise $\mathrm{Y}$. This is incoherent, as it amounts to $\mathrm{X}$ being best while some alternative $\mathrm{Y}$ is also best. Second, if some option $\mathrm{X}$ is best because the balance of pro tanto reasons favors that option, then there can nevertheless be a pro tanto reason for a compromise, and there can be pro tanto reason for compromising. It is just that these pro tanto reasons will be outweighed by other pro tanto reasons in favor of $\mathrm{X}$. This much should be uncontroversial. But a question that remains, I believe, is this: Could pro tanto reasons for compromising or pro tanto reasons for a compromise be part 
of the balance of pro tanto reasons that make some option all things considered best? When Adele initially prefers policy option $\mathrm{X}$ as all things considered best and reflects on her disagreement with Betty, could she end up thinking that $Y$ is the all things considered best option, where part of what makes $Y$ all things considered best is essentially connected to the fact of her disagreement with Betty? Could Adele have reasons for compromises or reasons for compromising that are triggered by her disagreement with Betty, such that the balance of reasons is decisively shifted from favoring $X$ to favoring $Y$ ? This is the question I will be concerned with.

It is quite important to distinguish this question about principled compromises from a distinct but related question. ${ }^{9}$ Suppose that Adele believes that policy $\mathrm{X}$ is the best policy, but this is conditional on everyone agreeing that $\mathrm{X}$ is best. So, Adele thinks that $\mathrm{X}$ conditional on consensus on $\mathrm{X}$ is better than any other policy conditional on agreement on that policy. Or suppose that illuminating account in (Wendt 2016), see especially chapter 3 on two levels of moral evaluation. 
Adele evaluates $\mathrm{X}$ as the best policy, while somehow abstracting from facts about the contentiousness of $X$ and alternatives to $X$ (say because policies are evaluated by features that can be assessed independently of facts about how well they are received by citizens who have to live with them). Let us say that when either of the above is true, then Adele believes that $\mathrm{X}$ is the ideally best policy. $^{10}$

Clearly, a policy being ideally best is different from a policy being all things considered best. When a policy $X$ is all things considered best it is superior to other policies given that all pro tanto moral reasons are taken into account, including those that in some lose sense depend on disagreement about various policies, say concern for peace, public justification, stability, would convince all others about, if we could do so at no cost (Wendt 2017, 198). This might correct, but I suspect that that is not informative as we do not have an independent grasp of what we one would convince others about at not cost. Why wouldn't we try to convince others about what is all things considered best? 
inclusion, accommodation, respect, and mutual recognition. ${ }^{11}$ Clearly, policies that are ideally best need not be all things considered best, and we don't have to regard them as such. Suppose, for example, that Adele knows that policy $\mathrm{X}$ would be quite controversial and unpopular, or that it would even violate individuals' right to a qualified consent if imposed on them against their will. In that case, while Adele might still think that $\mathrm{X}$ is ideally best, she surely should not think that $\mathrm{X}$ is best all things considered. ${ }^{12}$

One reason this is relevant is that we might follow Fabian Wendt, who in a recent contribution defines principled moral compromises in terms of

What makes a policy better than another policy might depend on degrees of compliance. If so, then even if everyone actually agrees what policy is ideally best, it does not follow that this policy is best all things considered. This can happen when compliance with the policy is low even when everyone agrees to the policy. If so, some other policy, that not everyone agrees about, but which nonetheless has a higher compliance, might be better all things considered.

Thanks to a reviewer for suggestions leading to these clarifications. 
the distinction between ideally best and all things considered best. ${ }^{13}$ On his view, we have principled reasons for compromises when we have moral reasons to deviate from the ideally best policy in favor of some policy that is all things considered best (or better that the ideal best policy). The moral reasons in question can concern peace or public justification (as Wendt argues), but might also include other matters. By contrast, we have pragmatic or instrumental reasons for compromises when what our reasons to depart from the ideally best policy are merely pragmatic or instrumental reasons. If moral compromises are defined in terms of morally justified deviations from ideally best policies in favor all things considered best options, then I suspect that there is no room for genuine debate whether principled compromises are possible.

(Wendt 2016). To me it seems more apt to talk about two different objects of evaluation at stake: the ideally best evaluates policies independently of issues about consent and controversy, whereas all things considered best evaluates the actual worlds in which policies are implemented. 
I have no objections to using the term 'moral compromise' for principled deviations from the ideal best in favor of the all things considered best. Clearly, however, this notion of moral compromise leaves us with a further question. Normally, we are concerned about what is all things considered best. Indeed, it might seem that this should always be our ultimate concern - it is hard to see why we would ever care about what is ideally best, except is this is part of an effort to identify the all things considered best. And generally, when we disagree about policies, we disagree about which policies are all things considered best. Suppose that Adele identifies $X$ as the all things considered best policy. Adele now learns that Betty does not agree that $\mathrm{X}$ is the all things considered best policy; rather she thinks that $Z$ is the best policy, also purporting to take all morally relevant factors into account. Now, do Adele and Betty have a principled reason to compromise in this case? This question does not even make sense if we reserve the word 'principled compromise' to principled deviations from the ideally best. While the common view might be that Adele and Betty should have reason to compromise, as I understand May, he argues that, in a sense, they have not. Once the all things considered best option has been identified, disagreement about what is all things considered 
best constitute no additional reason to depart from it. I return to May's argument in section 4 .

The plan for the rest of the paper is the following. I argue that moral disagreement is sometimes a reason reduce rational confidence in one's moral commitments (Section 5). Second, I argue that although reduced confidence in one's moral commitments does not itself constitute a pro tanto reason for compromising, or a pro tanto reason for any particular compromise (Section 6), reduced confidence may nonetheless facilitate pro tanto reasons for compromising, or pro tanto reasons for specific compromises (Section 7). When this occurs in a context of disagreement, pro tanto reasons for compromising or for specific compromises can affect what one should consider all things considered best. Before turning to my positive argument for the possibility of principled moral compromises, it will be helpful first to review May's arguments for his negative claim, and I do so in the next section.

\section{May on the impossibility of moral compromise}

May considers and rejects four reasons commonly invoked in support of the notion that Adele and Betty have principled reasons for compromise in the sort of situation depicted above. One argument is epistemic in nature, while the others appeal to putative moral reasons for compromises. The first argument 
appeals to complexity or fallibility: 'Principled compromise may be the best way to acknowledge our fallibility and the limitations of our ability to discern moral truth' (May 2005: 339). Second, one might appeal to respect: 'giving one's reasonable opponents the respect they deserve requires a willingness to appreciate their point of view and adjust one's position accordingly' (May 2005: 340). Third, May considers the view that one is morally obligated to accommodate one's opponents view in a workable moral compromise (May 2005: 342). Fourth, one might appeal to reciprocity: 'if a position on abortion is not morally acceptable to all reasonable people motivated to find mutually acceptable terms of cooperation, the value of reciprocity provides a principled reason to seek out an alternative that is.' (May 2005: 344)

To appreciate the force of May's arguments, consider first the appeal to complexity or fallibility (May 2005: 338-340). Assume that Jane is a proponent of a pro-choice abortion policy and that she in fact endorses the all things considered best policy. Assume that the all things considered best policy is about to be adopted as a result of a legitimate decision-making procedure that has been accepted by dissenting members of the community. The question for May is whether Jane now would have a reason to propose a compromise 
policy due to the complexity of and the controversy surrounding the abortion question.

May offers two reasons why Jane's recognition of the complexity of the dispute, and of her own fallibility, is not a valid ground for compromise in this context. First, if acknowledging the complexity of the issues should make Jane less certain about her own position, it should make her equally unsure about any proposed compromise position. As May notes, 'A policy that splits the moral difference between two opposing yet reasonable viewpoints need be no more self-evident than the viewpoints themselves' (May 2005: 339). So compromise positions need not be epistemically preferable to non-compromise positions.

Second, May points out that the complexity of the issues and the intractable nature of the disagreement do not constitute first order reasons for Jane to think that her view is wrong, or needs correction. A first-order reason is a moral reason for thinking that some part of a moral view is right or wrong. For instance, a commitment to the value of autonomy is a first-order reason to think that it is a mistake to hold that physician-assisted death is never morally permissible. But Jane's acknowledgement of her fallibility as a moral thinker is not a first-order reason to think that her view needs correction - as May 
remarks, 'this doubt is normatively inert' (May 2005: 339). Jane's acknowledgement of her fallibility may be a higher-order reason for reducing confidence in her view, but not for revising the content of her view.

Consider now moral reasons for principled compromises, that is, reasons having to do with respect, accommodation, inclusion and reciprocity. Why is Jane's respect for her fellow citizens not a reason for her to seek compromise when she disagrees with them about policy options? May argues:

'there are many ways to express respect without resorting to compromise. Jane can take the arguments of her pro-life opponents seriously and take time to respond to them appropriately. She can stick to criticisms of their arguments and eschew insulting ad hominem attacks. She can even form working relationships and alliances with regard to other matters. Yet none of this provides any principled reason for moral compromise.' (May 2005: 342)

Surely, sometimes one policy is morally better than another because it treats citizens more respectfully, and the same is true for moral concerns such as accommodation, inclusion and reciprocity. May's point is not that these concerns are irrelevant, but that once Jane has identified the all things 
considered best policy, where this includes due consideration for moral requirements such as respect, accommodation, inclusion and reciprocity, then further disagreement about what is all things considered best is not a reason for compromise. May argues that once we have identified the view we consider all things considered best, these epistemic and moral concerns might affect how we should hold a view in cases of disagreement, but they should not make us adjust what view we should hold. Acknowledgement of fallibility may be a higher-order reason for reducing one's confidence in one's moral view, but it is not a first-order reason for correcting one's view. Similarly, respect and inclusion might be reasons to take what one's opponents say in earnest, but they do not constitute reasons to change one's view if one has already accommodated the reasons and arguments one's interlocutors offer. Hence May concludes that, properly understood, there are no principled reasons for moral compromise. ${ }^{14}$ arguments that he rejects both. 
I believe that May is right in this. As I noted above, if an option is all things considered best, there cannot be a balance of pro tanto reasons that favor another option. And one cannot think that some option is all things considered best, and still believe that there are overriding reasons to prefer another option. One important thing to note while we should accept this, we should still freely acknowledge that concerns for respect, accommodation, inclusion and reciprocity and related moral concerns may be part of what makes some policy option all things considered best. If we think of these reasons as sometimes constituting pro tanto reasons for compromises and pro tanto reasons for compromising then clearly such reasons may be part of what makes an option all things considered best.

This much should, I believe, be uncontroversial. I now want to argue that disagreement about all things considered best policy options may affect the extent to which reasons for compromise and reasons for compromising impact on what we should regard all things considered best policies. When we disagree about what is all things considered best, this may increase the relative import of pro tanto reasons to compromise or for specific compromises. I elaborate this view in the remainder of the paper. As May points out, merely lowering one's confidence in one's moral views as a result of disagreement is 
normatively inert. I elaborate this point in Section 6, but in Section 7 I argue that reduced rational confidence in one's moral views may nonetheless result in pro tanto reasons for compromising and pro tanto reasons for certain compromises assuming a greater relative role in the balance of reasons, which in turn will affect what is the all things considered best policy. First, we need to consider why moral disagreement can generate a reason to reduce confidence in one's moral views.

\section{Why moral disagreement can generate a reason to reduce confidence}

In this section I argue that moral disagreement should often, though not always, lead us to reduce confidence in our moral views. The question before us is this. Prior to engaging in her disagreement with Betty, Adele is confident that her position on the relevant moral issue is correct, and that she has identified the all things considered best policy option. Now she reflects on the fact that Betty, who appears to be equally thoughtful and sincere, and who is likewise fully acquainted with the relevant arguments and evidence, sharply disagrees. Should this affect Adele's confidence in her view? 
A full discussion of the epistemology of moral disagreement is not possible here, but I will indicate why I think that moral disagreement often constitutes a reason to reduce rational confidence in one's moral views below. ${ }^{15}$ First, consider what we might call local disagreement on the one hand, and comprehensive disagreement on the other. Adele and Betty have a local disagreement when their basic disagreement depends on a single moral intuition. Suppose that Adele has a particular strongly felt moral intuition, say that criminal offenders deserve punishment. Betty has an equally strongly felt moral intuition that criminals do not per se deserve punishment. Other disagreements between Adele and Betty are either irrelevant to the issue at hand, or they are direct consequences of these conflicting moral intuitions.

Suppose that Adele and Betty now realize that this moral intuition is the only relevant factor that divides their views. How should they react to the mutual recognition of this fact? According to a plausible view, they should both be less confident in the veracity of their respective moral intuitions. Consider the 
situation as Adele sees it. ${ }^{16}$ She knows that she has a particular moral intuition, the origin of which she knows very little about. She also knows that Betty, who is in many respects in a comparable position, has an incompatible intuition. Adele has no particular higher order reason to believe that her intuition is correct, and that Betty's intuition is wrong. So, it is natural to think that the rational response for Adele is to reduce confidence that her intuition reflects a true moral proposition and Betty's a false one. ${ }^{17}$ Adele might still believe the propositional

Note that the various prominent views in the epistemology of disagreement agree that disagreement should often lead us to reduce confidence in the disputed beliefs. What these views disagree about are the exact details of this story, and about the ostensible existence of cases of peer disagreement in which one should not reduce confidence at all. Proponents of non-conciliationism or the steadfast view insist that there are such cases, where conciliationists deny their existence. Still, both sides agree that in many cases, the fact of disagreement is itself a reason to reduce confidence in the disputed belief. 
content of her intuition, but now with lesser confidence. Betty's situation is, of course, similar.

Most actual moral disagreements are not local in this sense rather, they involve larger complexes of considered intuitions, reflections about ethical principles of various levels of generality, counter-examples, debunking explanations of certain moral intuitions, reflections of theoretical virtues such as consistency, explanatory power and simplicity of their views, and so on. Comprehensive disagreements engage all the familiar features involved in reflective equilibrium. ${ }^{18}$ Obviously, there is a spectrum of cases of moral disagreements, ranging from extremely local to highly comprehensive, the most complicated of which are entertained perhaps only by professional philosophers.

Suppose now that Adele has a fully articulated comprehensive moral disagreement with Betty. This is to say that Adele has a clear grasp on which basic moral intuitions, normative assumptions and arguments her position depends upon. She is also fully aware of the full dialectic of possible 
counter-examples or counter-arguments to these normative assumptions, and of the counter-arguments to these counter-arguments. So, for any putative first order moral reason against her view that Adele is aware of, she also knows how to deflect or rebut that reason. Adele thus has a philosophically impeccable moral view. Imagine that Betty is in the same position as regards her disagreement with Adele, and that they are both aware of the symmetry.

Now, what should Adele do? As I have set up the case, Adele is not confronted with undefeated first order reasons to think that the moral position she espouses is wrong or in need of adjustment. Adele is, to be sure, aware of many putative first order reasons that suggest revision, but she knows how to respond to these. But Adele also knows that she disagrees with Betty, so she appreciates that at least one of them has gotten it wrong. She knows that Betty is as thoughtful and reflective as herself, and that Betty can defend her position just as well as Adele herself can. Still, Adele can infer that a least one of them must have weighed the balance of arguments in the wrong way. One or the other (or both) has placed too high a premium on simplicity over conservation of intuitions, or has perhaps fed the wrong set of moral intuitions into the equation, or has made some other mistake. However, Adele is not in a position 
to say with any certainty that she got it right and that Betty got it wrong. She should therefore reduce confidence in her view.

Relying on various versions of the method of reflective equilibrium, moral philosophers develop highly sophisticated views in ethical theory and political philosophy. Theoretical views in moral and political philosophy are defended by arguing that they are sufficiently simple, explanatorily powerful, and general, and that they receive adequate support from our considered moral intuitions. In part, this is a matter of showing that a stance in ethical theory or political philosophy can be defended against objections, typically arising from putative counter-intuitive implications or alleged incoherencies. Despite the great intellectual sophistication at play in these complex disagreements between moral philosophers, it seems that neither side to a dispute should be overly confident that they are correct in their views, even when these disagreements are fully articulated at the first-order level. This is not because we don't comprehend the dialectic involved, but because we lack a firm grip on how it all adds up. We do not well enough understand how we employ the method of reflective equilibrium (or any other method used to generate 
theoretical positions in moral philosophy) to be highly confident in the results, particularly when we know that our peers disagree with us. ${ }^{19}$

This is not to say that we should invariably conciliate in response to moral disagreement. Sometimes we have good reason to think that the source from whence our opponent derives his or her moral convictions is unlikely to be reflective of a sound moral view, for example, if these are derived from a source, the authority of which we have sound reason to question. I also do not assume that rational requirements to reduce confidence are always symmetrical; they may well not be. If your view is highly justified and mine is not, then it might be that I should reduce my credence more than you should. ${ }^{20}$ Of course, there are also cases in which disagreement and reflection on disagreement should force us to give up some part of our moral view entirely. I set these cases aside as they are not what ground compromises in the sense that we are interested in here. Finally, note that I do not assume that it is always transparent to us that 2013). 
we should reduce confidence in our views. Indeed, in most ordinary moral disagreements, people may well be under an epistemic obligation to reduce confidence in some of their moral commitments without realizing that this is so.

Sometimes professional moral philosophers realize that they disagree over substantive moral views with their peers, yet feel entitled to a very high degree of confidence that they are right. But even if we concede (as I argued we should not) that moral philosophers are indeed entitled to a high degree of rational credence in their moral views despite knowing that these views are contested by equally sophisticated colleagues, the vast majority of the moral views that fuel political disagreement are not of that nature. Most people are not trained philosophers, and hold most of their moral views in rather unreflective ways. Most hold the moral outlook that they do because they are raised in a culture promulgating these views, and not as a result of conscientious reflection. Learning that others disagree with such views is surely an indication that one should be less confident in disputed commitments, even if one may often not realize this.

\section{Why mere reduced confidence does not make compromises more attractive}

Assume now that disagreement sometimes constitutes a reason to reduce confidence in one's moral beliefs. The next question to be addressed is whether 
this grounds pro tanto reasons for compromising, or for specific compromises? I elaborate on why this is not immediately so in this section, using arguments the details of which differ from May's, though he would probably concur to what I argue. However, if we grant one further assumption, there is likely to be a fairly large class of cases in which moral disagreements do facilitate pro tanto reasons for compromise and for compromising. I return to this in Section 7.

Suppose that prior to engaging in their disagreement, Adele is very confident in her moral view $\mathrm{P}$, and Betty is equally confident in her view $\mathrm{Q}$. As a result, they are both very confident in their preferred policies, $X$ and $Z$. Now as a consequence of engaging in the disagreement, assume that Adele and Betty both rationally adjust their respective degrees of confidence in $\mathrm{P}$ and $\mathrm{Q}$ such that they become somewhat less assured in the moral commitments that separate them. As a result, they both become less rationally confident in their preferred policies $X$ and $Z$. Should the mere fact that their credences in their moral commitments $\mathrm{P}$ and $\mathrm{Q}$ have been lowered incline Adele and Betty towards compromising, or towards some compromise policy $Y$ ?

Suppose that after reflecting on the fact that they persistently disagree about $\mathrm{P}$ and $\mathrm{Q}$, Adele and Betty still rationally believe that their respective views are likely to be correct, although they are less confident than 
before. Assume, for instance, that they now each assign credence 0.6 to their respective moral views $P$ and $Q$, whereas prior to engaging in the disagreement they had assigned these views credence 0.9. Do Adele and Betty have a pro tanto reason for adopting any particular compromise position? Suppose that $Y$ is located somewhere on a scale between $\mathrm{X}$ and $\mathrm{Z}$. It is difficult to see why the mere fact that Adele and Betty have reduced their initial confidence should make them view any compromise position $Y$ as attractive. After all, although they now have reduced confidence in their respective positions, they presumably have still less confidence in any position that deviates from their initial position.

What, then, about pro tanto reasons for compromising? Again, it is difficult to see why Adele's lowered confidence, in its own right, should constitute a pro tanto reason for compromising with Betty. Why would the change in credence that results from engaging in the disagreement provide a reason for compromising?

Consider a different scenario. After deliberating and taking into account the fact that they disagree, Adele and Betty both assign 0.5 credence to the contested moral commitments. Do they now have a reason to accept a compromise? Even this need not be so. Suppose that while each has confidence 
in her own view to the degree of 0.5 , both still think it overwhelmingly likely that her opponent's view is false. Adele might be moved by her disagreement with Betty, and reduce confidence in her own view to the lowest possible level short of being more inclined than not to reject that view. Yet, Adele might still believe that Betty's view is very likely to be wrong. Why should this by itself move Adele to a position located in between her own and Betty's view?

How, it might be asked, can Adele become less convinced that her own view is correct without becoming more inclined to think that Betty is right? First, recall the assumption noted above, that $\mathrm{P}$ and $\mathrm{Q}$ are contrary propositions, not contradictory positions. Second, what may compel Adele to rationally reduce confidence in her view may be her observation that Betty does not seem to recognize the force of that view. This may cause Adele to question whether she has somehow made a mistake, even if she remains convinced that Betty's view is quite implausible. This is why Adele might rationally reduce confidence in her own view, but still think it overwhelmingly likely that Betty's view is incorrect. 
Finally, consider the radical scenario in which Adele and Betty both reduce their credence to 0.5 , while each assigns that same level of credence to the views of their opponent. ${ }^{21}$ So, assume that Adele and Betty assign credence 0.5 to both $\mathrm{P}$ and $\mathrm{Q}$, and accordingly, they no longer disagree about their moral commitments. Since, by assumption, Adele and Betty now share their moral commitments, and assuming that their policy preferences are determined by their moral commitments, Adele and Betty should now agree about what policy to adopt.

Do they have a reason to compromise in this scenario? Surely, one may question whether it is still appropriate to talk about compromise in this type of case. After all, Adele and Betty now agree on their moral outlook, and also agree as to what they consider the best policy. There is no residual disagreement between them calling for a compromise. So, it might be most natural to think of this third case as one of a convergence of views, rather than to each other's views in this symmetrical way, since we have assumed their views to be contraries. 
as one of compromise. It is still significant, however, that Adele and Betty converge on a view that is different from their initial views, and which they would not have arrived at were it not for their disagreement. This thus remains a case in which disagreement decisively influences what they should rationally consider all things considered best, though it may well be stretching the term too far to call it a compromise.

\section{The Reduced Weight Principle}

If what I have argued in the previous section is correct, merely reducing confidence in one's moral commitments does not itself generate pro tanto reasons for compromising, or for particular compromise positions. Yet, when we reduce rational confidence in our moral views as a response to disagreement, this can, in a different way, ground moral compromises - or so I will argue in this section.

To discuss these issues, it will now be useful to supplement the schematic case of moral disagreement about policy options with some 
additional structure. Suppose that Adele and Betty disagree about abortion. ${ }^{22}$ Adele holds the moral view $\mathrm{P}$, according to which the early fetus has no independent moral standing, say because it has neither sentience nor preferences regarding it's future or present, and is not numerically identical to any later individual. So, other moral concerns, such as those for autonomy, health and social consequences, will outweigh any moral concern for the early fetus. Suppose that this is why Adele favors a pro-choice policy $X$.

By contrast, Betty holds the moral view $Q$, according to which the embryo and early fetus enjoy full moral standing; intentionally terminating the existence of a human embryo is thus morally on a par with intentionally killing an innocent adult. According to Betty, this moral factor ultimately outweighs concern for women's autonomy, as well as concern for the negative social consequences of more restrictive access to abortion, and Betty's commitment to these views prompts her to support a pro-life policy Y. has objections to that particular issue, another case can be easily substituted. 
As should be clear from the case, Adele and Betty have a number of shared moral views. They both believe that the autonomy of women is a weighty moral concern, even if they disagree about whether this concern is outweighed by concern for a fetus or not. They are also in agreement that the societal and health-related consequences of any legislation on access to abortion matter, though they disagree as to which moral concerns might supersede such factors. Assume that Adele and Betty also acknowledge and agree that values such as respect, accommodation, inclusion and reciprocity should both ground and guide their treatment of others. Call these shared moral concerns $C$.

So, put very schematically, the case has the following structure. On the one hand, Adele believes that taken together, C and P strongly support prochoice policy X. Betty, on the other hand, believes that on balance, C and Q strongly support pro-life policy Z.

Suppose that prior to engaging in their discussion, Adele and Betty were highly confident in their respective moral views $P$ and $Q$, but upon learning that they are in disagreement, each is rationally compelled to reduce confidence in her moral belief. Assume that Adele and Betty still have most rational confidence in their pre-deliberation moral views, even if their confidence has 
decreased somewhat as a result of reflecting on the disagreement. As noted in the previous section, merely reducing rational confidence in one's moral view does not seem to generate a reason for compromising. While this is true, I suggest that Adele and Betty should nonetheless attach less weight to their moral commitments $\mathrm{P}$ and $\mathrm{Q}$, now that they have less rational confidence in them. To see why, consider the following:

The Reduced Weight Principle. When A assigns lesser credence to the truth of a moral commitment, then A should assign lesser weight to the moral factors identified by that commitment. ${ }^{23}$ form of externalism about moral reasons is false. According to this form of externalism, whatever moral reasons or factors exist, they exert the same force on us, whether we know about them or not. If we grant the truth of this or similar forms of externalism, the reduced weight principle would have to be restated in terms of subjective moral obligation, or subjective rightness, where 
According to the Reduced Weight Principle, Adele should assign lesser weight to her moral commitment $\mathrm{P}$, and Betty should similarly give lesser weight to her commitment $Q$, as a result of their lowered rational confidence in these commitments.

As far as I am aware, there are no discussions of principles like the Reduced Weight Principle, so one might wonder if it is plausible at all. Some reflection suggests that it is. If one is fully confident in the truth of a moral commitment, then surely one should assign full weight to the moral factors it identifies; not doing so would seem irrational. If one is fully confident that a commitment is false, one should, of course, assign the factors identified by that commitment no weight at all. But suppose that one assigns some credence in between these two extremes to some moral commitment. What should one do? It would be odd to assign the moral factors identified no weight at all, but it would also be peculiar to assign them full weight, as if one believed the

subjective obligation or rightness is a function of what subjects reasonably believe about objective rightness. 
commitment fully. So, the only option seems to be to accept some reduction in the weight apportioned to the moral factors identified by a particular moral principle, in response to reduced confidence in the truth of that principle. When one is less confident in the validity of a purported moral reason or factor, then that reason or factor should have less traction in one's moral thinking. This is what the Reduced Weight Principle says, and I suggest that this is plausible.

If The Reduced Weight Principle is correct, disagreement may in some cases engender significant reasons for compromises, or for compromising, regarding what is all things considered best. When our moral commitments are challenged by disagreement, this should sometimes make us less confident in their truth. When this happens, the moral factors identified by these commitments should assume less weight in the total array of pro tanto reasons, even if we still, on balance, have more confidence that our moral commitments are correct than not. This will give more relative weight to undisputed moral commitments, including the sort of moral reasons for compromising that we discussed earlier. In some cases, this can affect the balance of reasons, and ultimately change what we have all things considered most reason to do, or what is all things considered best. If we do share moral commitments of certain types, disagreement about other commitments may 
affect our reasons for compromise or reasons for compromising, and this may affect what we have all things considered most reasons to. In this sense, moral disagreement may give rise to or enable principled compromises.

\section{But are these genuine compromises?}

If what I have argued above is correct, we should often reduce confidence in our moral commitments in response to moral disagreement. Pro tanto reasons for compromising and pro tanto reasons for compromise can be part of the balance of pro tanto reasons that make some option $Y$ all things considered best, where $Y$ differs from initially preferred policy options $X$ and $Z{ }^{24}$ If the Reduced Weight Principle is correct, the implication is that pro tanto reasons to compromise and pro tanto reasons for particular compromises will sometimes

for a compromise position in every disagreement that we encounter. Moreover, this does not say that we rationally converge on a compromise position, even if our ultimate positions are partly shaped by pro tanto reasons for compromising, or for compromise positions. Being moved towards a compromise and converging on a compromise are importantly distinct. 
assume greater relative weight in the total array of reasons when we have moral disagreements about all things considered best polices. This will affect what we should think is all things considered best, pressing us away from extremes and toward what may be described as compromise positions.

We can express this in terms of a distinction between predisagreement views and post-disagreement views regarding all things considered best policy-options. Adele's pre-disagreement view is Adele's view prior to any warranted reduction of rational credence in moral commitments due to moral disagreement with Betty. Adele's post-disagreement view is the view she holds when her credences has been adjusted in response to moral disagreement. Note that we should not be confined to a temporal interpretation of the distinction temporally: it might be that only the post-disagreement situation actually exists, and that the pre-disagreement is merely a hypothetical comparison. $^{25}$

I will now consider a number of objections to the proposed account of principled compromises. While there are several distinct objections to 
address, they all concern whether what the view describes is most aptly described as a compromise.

First, as May and many others have pointed out, compromising and correcting one's view seems distinct, and one may require that an account of principled compromises respect this distinction. In some sense, compromising is different from changing one's view.

On the present account principled compromises about all things considered best policies trivially involves a change of belief. Adele's predisagreement view is that $X$ is the best policy option, whereas her postdisagreement view is that $\mathrm{Y}$ is best, so surely Adele has changed her view. Alternatively, we might say that Adele's pre-disagreement view is the view that Adele would hold, if she did not have her disagreement with Betty to take into account. In this case, Adele adopting her post-disagreement is not aptly characterized as a change of view. Yet, both scenarios might lead one to question whether we should speak of compromise. In the first case because it is a change of view, in the second case because Adele simply arrives at what she considers all things considered best.

I find it implausible that this should prevent us from talking about compromises in such cases. Agents should always prefer what they think is all 
things considered best. So, any view of compromising regarding all things considered best policies will include an account of changing one's mind about what is all things considered best, or an account of how one arrives at a view about what is all things considered best in response to principled reasons for compromise. It would be odd to deny the possibility of compromises regarding all things considered best policies, because anything that meets this description would either be a change of view regarding what is all things considered best, or arriving at a view about what is all things considered best.

Alternatively, and more plausibly, one might suggest that a compromise regarding all things considered best positions require that the underlying moral commitments remain unchanged - otherwise it is a correction. The proposed account of principled compromises goes some way to meet this requirement. First, the account preserves a sense in which one can compromise without abandoning one's underlying moral commitments. Undertaking a moral commitment by affirming a moral proposition, but becoming less confident about it, may still involve affirming it, and is distinct from flat out rejecting it. Second, the change in credence driving the compromise are assumed to occur in response to the significance of disagreement that one has with fellow citizens. They are not assumed to arise in response to first order moral arguments 
implying that one's moral commitments are false, or to a discovery that one as overlooked first order reasons, or made a reasoning mistake. So, even if there is a change in view, it is not an ordinary correction of a mistake.

This makes some sense of the idea that even if one settles for a compromise one would still prefer to convince one's opponent about one's predisagreement view. Suppose that Adele as a result of disagreement with Betty now is less confident about the truth of a decisive moral assumption $\mathrm{P}$, but still think that there are good reasons for it - it is just that she cannot convince Betty about P. Clearly, Adele might still think that she should convince Betty about the truth of $\mathrm{P}$, and Adele can rationally think that were she to convince Betty about this, then this would entitle her to regain full confidence in P. Similarly, it is often suggested that compromises are by nature painful; a compromise essentially requires acquiescing to a policy that one continues to find morally inferior. Again, the account preserves this feature, at least partially. When she compromises, Adele may still consider moral principle $\mathrm{P}$ to be correct, though she less rationally confident in $\mathrm{P}$ and accordingly assigns lesser relative weight to the moral factors identified by P. But in so far as Adele still commits to P, there is a sense in which she can regret adopting $Y$, while still thinking that $Y$ is all things considered best. 
As I said, the account goes some way in preserving a sharp difference between compromises and corrections. Clearly, however, the account cannot go all the way. If a reduction in credence in a moral proposition is large enough, then it amounts to a rejection of the proposition. Note also that I assumed in the above that preserving the same propositional content, while changing one's credence, is not a change of view, and thus not a correction. But of course, on an equally natural reading of 'change of view', it is just that.

I submit, however, that a requirement that principled moral compromise should involve a change in belief about what is best all things considered, but no change in underlying moral commitments, cannot be met. To see this, suppose for a moment that a principled compromise requires the following: (i) that one's moral commitments (the pro tanto reasons that one recognizes) remains unaltered, (ii) that one undergoes a change in view regarding what policy is best all things considered, and (iii) that this change in view is motivated by a recognition of moral reasons to compromise. These requirements are not mutually satisfiable. If condition (iii) is met, then condition (i) is violated; if condition (iii) is not met, then condition (i) might be, but in that case one's view about what is all things considered best can hardly count as a 
principled compromise, as it will have to be motivated by reasons that one does not recognize as residing in moral commitments.

Rather than concluding that principled moral compromises are impossible, I suggest that we reject condition (i). This means that we acknowledge that principled compromises regarding the all things considere best arises in response to an altered set of pro tanto reasons, and in this sense they involve a change of mind not only about what is all things considered best, but also regarding the nature and balance of pro tanto reasons. If we instead were to conclude that genuine compromises regarding all things considered best polices are not possible, we should also admit that the notion of principled compromise is of less interest. No matter what we opt for, the overarching question remains in place, and this is the question what we should do when we disagree about moral questions and how this should affect the policies that we consider all things considered best. Whether the outcomes of such processes 
conform to our pre-theoretical views about what counts as a compromise may ultimately not be so important. ${ }^{26}$

Second, it may be thought that compromises should involve an element of negotiation or reciprocity: when you and I compromise, I accept what I consider to be an inferior option, but in return, you agree to make similar concessions on your part. Clearly, this element of bargaining and making reciprocal concessions is lacking in the account of compromise given here. According to the present account, I should adjust my confidence in my moral commitments in response to my disagreement with you, and this should make me reconsider what is the all things considered best policy option, but I need not negotiate this question with you, and the extent to which I should reduce my confidence in a contested moral commitment is ultimately independent of any political deal we might strike. Some might think that it is a weakness of the account of compromise on offer that this element of bargaining is missing. If anything, I believe this to be an advantage of the account in as much as it helps the differences between corrections and compromises. 
to preserve a distinction between negotiating a political deal and having a principled reason for compromise. Bargaining should be distinct from the act of compromising, and the present account preserves this.

A third worry might be the following. Suppose that Adele and Betty share a common moral commitment that has nothing to do with reasons that are grounded in values like inclusion, accommodation, respect or reciprocity. To illustrate with another example, suppose that Adele thinks that liberty and efficiency are of utmost importance, while equality is not, whereas Betty thinks that concerns about equality and efficiency should have great weight, whereas liberty should not. Since Adele and Betty primarily disagree about liberty and equality, we can imagine that the policy position each end up they end up endorsing is, to a significant extent, determined by their shared concern for efficiency. Basically, they bracket the moral concerns that divide them, and devise policies based on what they have in common. The question now is why we should think of this as a compromise between Adele and Betty? In reply to this, it might be pointed out that relative to their respective moral commitments, both Adele and Betty must view their resulting positions as inferior to the policy options they would have preferred independently of their 
disagreement. It is this that makes it appropriate to refer to the resulting position as a compromise.

A final concern may be that positions adopted as compromises in the way I have described need not look like compromises at all. Above we assumed that compromises involve policy options that can be ordered on a scale connecting two extremes. Call this a scalar compromise. Like the issue of taxation, many policy disagreements permit scalar compromises. Other cases that come to mind are speed limits, age limits on alcohol, and the minimum wage. Even the question of abortion could permit of scalar compromises. A compromise position on abortion could concern the stage in pregnancy at which the abortion can be legally performed, and again, this could be represented on a temporal scale. ${ }^{27}$ However, scalar compromises may be only one among several different types of compromise. Consider the public controversy over the use of genetically modified crops. Roughly, some are in intended to illustrate formal features of compromises, not realistic policy options. 
favor of very restrictive legislation, or of a ban on the use of genetically modified crops, making it quite costly or impossible to market such products. Others disagree; seeing no particular problem with the use of genetically modified crops, some think that these products should be subject to no more or less regulation than ordinary crops. There is a well-known, intermediary position that simply recommends mandatory labeling of food products containing genetically modified crops. ${ }^{28}$ This is an instance of what one might label a liberal compromise. It is easy to see that there may exist liberal compromises in a range of morally laden political controversies - think of same sex marriages, physician-assisted death, or vegetarianism. ${ }^{29} \mathrm{~A}$ liberal compromise is not usefully described as a policy option that is somehow located on a spectrum between two policy extremes. But liberal compromise may nonetheless be attractive in virtue of their ability to accommodate a range of diverse moral

See also (Weinstock 2013) on other distinctions among types of compromise. 2014) and the references therein. 
views. Indeed, when a liberal compromise is found, it may offer a solution to some moral conflict that is superior to any other potential compromise position. Even if one is disinclined to think of liberal compromises as genuine compromises, one must concede that they share a number of important features of a compromise. A liberal compromise arises in response to disagreement, and it can be motivated in part by a perceived reason to accommodate sincerely held views of fellow citizens. Moreover, a liberal compromise can be painful in that it can be considered inferior relative to the compromisers' basic moral commitments.

No doubt some will still consider the category of compromises that emerges from this account as too broad to really warrant the label. I am not convinced that 'compromise' has such a precise and stable pre-theoretical meaning so as to warrant this form of linguistic legislation. Ultimately, the issue may turn on what stipulation of the word we decide to work with in philosophy, and I am inclined to think that we should set these questions aside as largely terminological. The question of overall importance is how recalcitrant disagreement about moral issues should feature in what policy we end up thinking is the all things considered best. This is a significant question in its own 
right, and whether the resulting positions should be regarded as compromises is of secondary importance.

\section{Concluding remarks}

My aim in this paper has been to develop an account of how moral disagreement can ground principled reasons for compromise. May argues that disagreement never provides principled moral reasons for compromise. I have maintained that his argument overlooks how the balance of pro tanto reasons may be affected by changes in levels of rational confidence in disputed moral commitments. Moral disagreement should sometimes lead us to reduce confidence in our underlying moral commitments. Assuming the truth of the Reduced Weight Principle, this yields greater relative weight to pro tanto reasons for compromising, or pro tanto reasons for particular compromise positions, and this may be part of what determines the all things considered best position. Moral disagreement thus facilitates principled moral compromises by reducing the impact of the moral views that set us apart, thereby increasing the relative import of what binds us together. 


\section{References}

Bellamy, R. \& Hollis, M., 1999. Consensus, Neutrality and Compromise. In Pluralism and Liberal Neutrality. pp. 54-79.

Bird, C., 1996. Mutual Respect and Neutral Justification. Ethics, 107, pp.62-96.

Brink, D.O., 1989. Moral realism and the foundations of ethics, Cambridge: Cambridge University Press.

Carens, J., 1979. Compromises in Politics. In R. Pennoch \& J. Chapman, eds. Nomos XXI: Compromises in Ethics, Law, and Politics. New York: New York University Press, pp. 123-42.

Christensen, D., 2011. Disagreement, Question-Begging and Epistemic SelfCriticism. Philosophers Imprint, 11(6).

Christensen, D., 2007. Epistemology of Disagreement: The Good News. Philosophical Review, 116(2), pp.187-217.

Daniels, N., 1979. Wide Reflective Equilibrium and Theory Acceptance in Ethics. The Journal of Philosophy, 76(5), pp.256-282.

Dobel, P., 1990. Compromise and Political Action: Political Morality in Liberal and Democratic Life, Savage, Maryland: Rowman \& Littlefield.

Frances, B., 2013. Philosophical Renegades. In J. Lackey \& D. Christensen, eds. The Epistemology of Disagreement. Oxford University Press, pp. 121-166. 
Huxtable, R., 2014. Splitting the Difference? Principled Compromise and Assisted Dying. Bioethics, 28(9), pp.472-480.

Jones, P. \& O'Flynn, I., 2012. Can a compromise be fair? Politics, Philosophy \& Economics, 12(2), pp.115-135.

Kelly, T., 2010. Peer Disagreement and Higher-Order Evidence. In R. Feldman \& T. A. Warfield, eds. Disagreement. Oxford University Press.

Knight, C., 2006. The Method of Reflective Equilibrium: Wide, Radical, Fallible, Plausible. Philosophical Papers, 35(2), pp.205-229.

Macedo, S., 1990. Liberal Virtues: Citizenship, Virtue, and Community in Liberal Constitutionalism, Oxford: Clarendon Press.

May, S.C., 2013. Compromise. In H. La Follette, ed. The International Encyclopedia of Ethics. Wiley, pp. 959-968.

May, S.C., 2011. Moral compromise, civic friendship, and political reconciliation. Critical Review of International Social and Political Philosophy, 14, pp.581-602.

May, S.C., 2005. Principled compromise and the abortion controversy. Philosophy and Public Affairs, 33(4), pp.317-348.

Wedgwood, R., 2010. The Moral Evil Demons. In R. Feldman \& T. Warfield, eds. Disagreement. Oxford University Press. 
Weinstock, D., 2013. On the possibility of principled moral compromise. Critical Review of International Social and Political Philosophy, 16(4), pp.537-556.

Wendt, F., 2016. Compromise, Peace, and Public Justification, Palgrave Macmillan.

Wong, D., 1992. Coping with Moral Conflict and Ambiguity. Ethics, 102, pp.763784. 